\title{
Effects of tiotropium on sympathetic activation during exercise in stable chronic obstructive pulmonary disease patients
}

This article was published in the following Dove Press journal:

International Journal of COPD

16 February 2012

Number of times this article has been viewed

\author{
Kenji Yoshimura \\ Ryoji Maekura \\ Toru Hiraga \\ Seigo Kitada \\ Keisuke Miki \\ Mari Miki \\ Yoshitaka Tateishi \\ Department of Respiratory Medicine, \\ Toneyama National Hospital, Osaka, \\ Japan
}

Background: Tiotropium partially relieves exertional dyspnea and reduces the risk of congestive heart failure in chronic obstructive pulmonary disease (COPD) patients. However, its effect on the sympathetic activation response to exercise is unknown.

Aims: This study aimed to determine whether tiotropium use results in a sustained reduction in sympathetic activation during exercise.

Methods: We conducted a 12-week, open-label (treatments: tiotropium $18 \mu \mathrm{g}$ or oxitropium $0.2 \mathrm{mg} \times 3 \mathrm{mg}$ ), crossover study in $17 \mathrm{COPD}$ patients. Treatment order was randomized across subjects. The subjects underwent a pulmonary function test and two modes of cardiopulmonary exercise (constant work rate and incremental exercise) testing using a cycle ergometer, with measurement of arterial catecholamines after each treatment period.

Results: Forced expiratory volume in 1 second and forced vital capacity were significantly larger in the tiotropium treatment group. In constant exercise testing, exercise endurance time was longer, with improvement in dyspnea during exercise and reduction in dynamic hyperinflation in the tiotropium treatment group. Similarly, in incremental exercise testing, exercise time, carbon dioxide production, and minute ventilation at peak exercise were significantly higher in the tiotropium treatment group. Plasma norepinephrine concentrations and dyspnea intensity were also lower during submaximal isotime exercise and throughout the incremental workload exercise in the tiotropium treatment group.

Conclusion: Tiotropium suppressed the increase of sympathetic activation during exercise at the end of the 6-week treatment, as compared with the effect of oxipropium. This effect might be attributed to improvement in lung function and exercise capacity and reduction in exertional dyspnea, which were associated with decreases in respiratory frequency and heart rate and reduced progression of arterial acidosis.

Keywords: chronic obstructive pulmonary disease (COPD), anticholinergics, exercise testing, sympathetic activation

\section{Introduction}

Bronchodilator medications (including anticholinergics, $\beta_{2}$-agonists, and methylxanthines) are central to symptomatic management of chronic obstructive pulmonary disease (COPD). ${ }^{1}$ Inhaled anticholinergics include the short-acting muscarinic antagonist ipratropium bromide and oxitropium bromide, and the M1- and M3-selective long-acting muscarinic antagonist tiotropium bromide. Regular use of a short- or long-acting anticholinergic improves dyspnea, exacerbations, health-related quality of life, and lung function in COPD patients. ${ }^{2,3}$ It was widely believed that anticholinergic inhalation therapy may exacerbate congestive heart failure because of its cholinergic effects (eg, tachycardia and activation of the sympathetic nerve system). A negative association between treatment with
Correspondence: Ryoji Maekura

Department of Respiratory Medicine,

Toneyama National Hospital, 5-I-I

Toneyama Toyonaka-city,

Osaka 560-8552, Japan

Tel +8I 668532001

Fax +81668531221

Email rmaekura@toneyama.go.jp 
ipratropium and an increase in cardiovascular (CV) mortality was noted in an earlier report from the Lung Health Study. ${ }^{4}$ Moreover, no statistically significant differences were found in all-cause mortality or CV mortality between tiotropium and placebo or ipratropium. ${ }^{5}$ However, tiotropium also significantly improves scores on the St George's Respiratory Questionnaire and reduces the likelihood of COPD exacerbation when compared with ipratropium. ${ }^{2,3,6}$ Tiotropium therapy is suggested to increase endurance by reducing hyperinflation. ${ }^{6}$ Recently, the UPLIFT (Understanding Potential Long-term Impacts on Function with Tiotropium) trial demonstrated that tiotropium provides sustained improvements in lung function as well as improved health-related quality of life, reduced exacerbation, and increased survival without altering the rate of decline in the mean forced expiratory volume in 1 second $\left(\mathrm{FEV}_{1}\right)$ as compared with the placebo group. ${ }^{7,8}$ Furthermore, tiotropium was associated with a reduction in the risk of CV mortality and $\mathrm{CV}$ events. ${ }^{7,8}$ Therefore, although one study has not found differences in mortality, there seems to be a noticeable difference between short-acting and long-acting muscarinic antagonists in terms of CV mortality as found in the other studies.

We have previously reported that the pathophysiology of COPD during exercise differs significantly among patients with different exercise capacities. ${ }^{9}{ }^{10}$ Patients with lower exercise capacity, whose survival prognosis is extremely poor, suffer from sympathetic overactivation, severe gas exchange disorder, and ventilatory disturbance during daily activity. It is well known that enhanced sympathetic nerve activity, as evidenced by an increased plasma norepinephrine level, is deleterious for the pathophysiology of congestive heart failure. We hypothesized that use of tiotropium would be associated with sustained reduction in sympathetic activation during exercise, due to improvements in exertional dyspnea and exercise performance in patients with COPD. In addition, differences in pathophysiology during exercise between the two types of muscarinic antagonist are not well understood. Therefore, we conducted a randomized, 12-week, open-label (tiotropium: long-acting muscarinic antagonist, and oxitropium: short-acting muscarinic antagonist), crossover study using cardiopulmonary exercise testing (CPET) to evaluate differences between the two drugs in the pathophysiology (especially in sympathetic activation and dynamic hyperinflation) during exercise in stable patients with COPD.

\section{Methods}

\section{Subjects}

Subjects included clinically stable outpatients with COPD aged $\geq 40$ years, with a cigarette smoking history of $\geq 10$ pack-years and postbronchodilator $\mathrm{FEV}_{1} /$ forced vital capacity (FVC) $<70 \%$ and $\mathrm{FEV}_{1}<80 \%$ of the predicted value. Patients with the following conditions were excluded: (1) significant diseases other than COPD that could contribute to dyspnea and exercise limitation; (2) a history of asthma, allergic rhinitis, or atopy; (3) a blood eosinophil count of $\geq 600 / \mu \mathrm{L}$; (4) treatment with an anti-allergic drug or antihistamine drug; (5) change in the dose of steroid inhalation, oral $\beta_{2}$ stimulant, theophylline preparation, or expectorant within 1 month prior to the screening test; (6) treatment with an angiotensin-converting enzyme inhibitor or change in the dose of an angiotensin-converting enzyme inhibitor within 1 month prior to the screening test; (7) symptomatic glaucoma or prostatic hypertrophy; (8) tuberculosis (currently active) or definite sequela of tuberculosis; (9) recent history of carcinoma (within the past 5 years); (10) history of lung surgical resection; (11) important contraindications for clinical exercise testing; (12) exercise limitations not related to fatigue or exertional dyspnea; (13) recent onset of upper airway infection (within 1 month prior to the screening test); or (14) participation in a rehabilitation program for COPD within 6 weeks prior to the screening visit. Concomitant use of $\beta$-blockers was prohibited.

Concomitant respiratory medication was permitted if the patient's condition was stable for at least 1 month prior to and throughout the duration of the study. Permitted medication included regular intake of the drugs required for the management of COPD, such as oral corticosteroids and inhaled corticosteroids, oral theophylline preparations, oral $\beta$-adrenergics and long-acting inhaled $\beta$-adrenergics, and mucolytic agents not containing bronchodilators. Inhaled corticosteroids, oral theophylline preparations, oral $\beta$-adrenergics, and long-acting inhaled $\beta$-adrenergics were washed out at least 24 hours prior to the pulmonary function testing days of Visit 2, Visit 3, and Visit 4. Open-label salbutamol (metered-dose inhaler: $100 \mu \mathrm{g} \cdot$ actuation $^{-1}$ ) was provided as rescue medication during the run-in and treatment periods but was withheld for 12 hours prior to each visit. Medication not allowed for at least 1 month prior to the beginning of the run-in period and throughout the study period included the following: ipratropium bromide, all $\beta$-blockers, antileukotrienes, cromolyn sodium and nedocromil sodium, antihistamines (H1 receptor antagonists), tricyclic antidepressants, and monoamine oxidase inhibitors.

\section{Study design}

We conducted a randomized, 12-week, open-label, crossover study in 17 stable patients with COPD (women:men, 3:14, 
$68.7 \pm 1.9$ years). The research protocol used in this study was approved by the institutional review board of the National Hospital Organization Toneyama Hospital, Osaka, Japan, for experimentation on human subjects, and complies with the Declaration of Helsinki for studies involving humans. All patients gave their written informed consent before study enrolment.

During an initial screening visit (Visit 1), patients were assessed for their eligibility to participate in the study. At this visit, patients performed pulmonary function tests (body plethysmography, spirometry, and single-breath diffusing capacity). On Visit 2 (4 weeks after Visit 1), patients were randomized to 6 -week treatment periods with either $18 \mu \mathrm{g}$ tiotropium (Spiriva ${ }^{\circledR}$; Boehringer Ingelheim, Ingelheim, Germany) or $0.2 \mathrm{mg}$ oxitropium inhalation aerosol (Tersigan ${ }^{\circledR}$; Boehringer Ingelheim). Tiotropium is a long-acting muscarinic antagonist and was taken once daily at 7:00 am. Oxitropium has a relatively short duration of action that requires administration every 6-8 hours, and was taken three times daily at 7:00 am, 2:00 pm, and 9:00 pm. Potential carryover effects from the first treatment are not relevant, due to the short-term effects of either drug treatment. On Visit 3 after the initial 6-week treatment, patients underwent the pulmonary function tests, symptom-limited incremental CPET with progressive increments of $10 \mathrm{~W}$ every 2 minutes, and symptom-limited constant-load (intensity at $75 \%$ of maximal work capacity) CPET using a cycle ergometer between 12:00 pm and 3:00 pm (Assessment 1). After Assessment 1, the second 6-week intervention was performed. After the second 6-week treatment period, the same assessments were performed as after the first treatment period (Assessment 2). We compared all parameters between the tiotropium and oxitropium treatment groups. A schematic representation of the study design is shown in Figure 1.

\section{Pulmonary function test and cardiopulmonary exercise testing}

Pulmonary function data were measured for all subjects with an Autospirometer System 9 (Minato Medical Science,

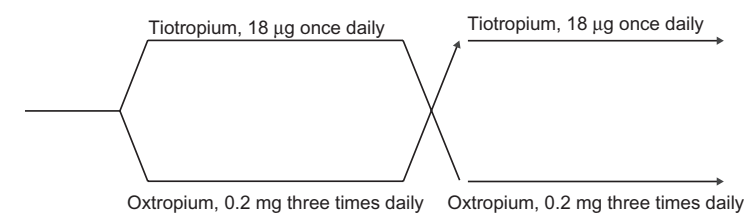

$\longmapsto_{\text {Visit 1 }}^{(4 \text { weeks })}$
Visit 2

Figure I Study design.
Tokyo, Japan) and CHESTAC-3000 DN (Chest, Tokyo, Japan) following the manufacturers' recommendations. ${ }^{11}$ All spirometric tests were conducted in triplicate, and the highest measurements were used for subsequent analyses. On Visits 3 and 4, progressive increment CPET starting at $10 \mathrm{~W}$ and increasing by $10 \mathrm{~W} / 2$ minutes was performed by all patients first, and symptom-limited constant-load CPET (intensity at $75 \%$ of maximal work capacity) was then performed after resting for more than 30 minutes. ${ }^{9,12,13}$ CPET was discontinued when the subjects experienced marked breathlessness and/or leg fatigue. Expired gas data were collected breath by breath using a Vmax (Sensor Medics Corporation, Yorba Linda, CA). The following measurements were recorded as 30-second means: (1) "rest" was defined as the end of the 3-minute resting period; (2) exercise data were collected during the fourth 30-second period of each 2-minute interval of exercise; and (3) "peak" values were defined as the mean of the last 30 seconds of loaded exercise. Subjects rated the intensity of their breathing discomfort using the modified Borg scale at rest, within the last 10 -second period of each 1-minute interval during exercise and at the end of the exercise.

During incremental CPET, arterial blood samples were drawn through an indwelling radial artery cannula placed under local anesthesia. These samples were taken before exercise when the patient was sitting, during the last 10 seconds of each 2-minute interval exercise stage, and at the end of the exercise. Arterial blood gases (arterial oxygen pressure and arterial carbon dioxide pressure), $\mathrm{pH}$, and plasma lactate were measured using a blood gas analyzer (ABL-800; Radiometer Medical Aps, Tokyo, Japan) immediately after sampling. In addition, concentrations of arterial plasma catecholamines (norepinephrine and epinephrine) were measured using highpressure liquid chromatography.

During constant-load CPET, an inspiratory capacity maneuver was performed at rest within the last 30-second period of each 2-minute interval exercise stage during exercise and at the end of exercise. Four main time points were used for the evaluation of exercise parameters: ie, preexercise rest, 2-minute exercise, submaximal isotime, and peak exercise. "Submaximal isotime" was defined as the end of the stage 2 minutes prior to the time of shorter peak exercise either during the period of tiotropium treatment or during the period of oxitropium treatment. Values at isotime were measured directly. Measured CPET parameters included heart rate (HR), respiratory frequency, tidal volume, minute ventilation (VE), oxygen uptake, ventilatory equivalent for oxygen and ventilatory equivalent for carbon dioxide, 
and oxygen pulse. Maximum voluntary ventilation (MVV) was indirectly calculated as $\mathrm{MVV}(\mathrm{L} /$ minute $)=\mathrm{FEV}_{1.0}$ (L) $\times 35 /$ minute. The dyspnea index $(\%)=[\mathrm{VE}(\mathrm{L} / \mathrm{minute})$ at peak exercise $] /[\mathrm{MVV}(\mathrm{L} /$ minute $) \times 100]$ and the predicted maximum HR (adult) $=220-$ age $($ years $)$.

\section{Dyspnea evaluation}

The intensity of dyspnea was evaluated using the Borg scale during exercise testing. ${ }^{14}$ Before testing, the Borg scale was explained and its endpoints were anchored such that 0 indicated "no difficulty in breathing" and 10 represented "the most severe (maximal) difficulty in breathing that the subject had previously experienced or could imagine." By pointing to the Borg scale, subjects rated dyspnea at rest, every minute during exercise, and at peak exercise. Immediately after exercise cessation and completion of mechanical measurements, subjects were asked the reason(s) for exercise termination (ie, dyspnea, leg fatigue, both, or other).

\section{Statistical analysis}

Statistical analyses were performed using JMP Start Statistics ( $\mathrm{JMP}^{\circledR} 9$; SAS Institute Inc, Cary, NC). Values in tables and text are expressed as mean \pm standard deviation. Bars in figures are expressed as mean \pm standard error. Differences between the two groups were statistically analyzed using the crossover analysis of variance. Relationships between plasma norepinephrine levels and the other parameters obtained during CPET were assessed using simple and multiple (backward variable selection, $P<0.05$ ) regression analyses. The results were considered statistically significant when $P<0.05$. No correction for multiple testing was made.

\section{Results}

Table 1 compares static parameters between the treatments with tiotropium and oxitropium. $\mathrm{FEV}_{1}$ and FVC were significantly ( $P=0.003$ and $P=0.002$, respectively) greater in the tiotropium group than in the oxitropium group. The arterial oxygen pressure $(P=0.002)$ significantly improved during the treatment with tiotropium, although no differences were found in VE and oxygen uptake. There were no differences in the concentrations of norepinephrine or lactate between the groups at rest.

In the constant workload exercise tests, the endurance time was significantly longer in the tiotropium group, including five patients with shorter endurance time; however, the peak oxygen uptake was significantly smaller than that in the oxitropium group (Table 2 and Figure 2). The dyspnea index (peak VE/MVV) was also significantly $(P=0.002)$ lower in
Table I Comparison of the static parameters between treatments with tiotropium and oxitropium

\begin{tabular}{|c|c|c|c|}
\hline & Tiotropium & Oxitropium & $P$ value \\
\hline Body mass index $\left(\mathrm{kg} / \mathrm{m}^{2}\right)$ & $22.3 \pm 2.3$ & $22.2 \pm 2.4$ & \\
\hline $\mathrm{FEV}_{1}(\mathrm{~L})$ & $1.06 \pm 0.39$ & $0.97 \pm 0.43$ & 0.003 \\
\hline$\% \mathrm{FEV}_{1}$ (\% pred) & $42.0 \pm 14.7$ & $38.6 \pm 16.4$ & 0.003 \\
\hline FVC (L) & $2.33 \pm 0.74$ & $2.05 \pm 0.77$ & 0.002 \\
\hline FVC (\% pred) & $75.8 \pm 18.4$ & $66.9 \pm 21.0$ & 0.002 \\
\hline $\mathrm{FEV}_{1} / \mathrm{FVC}(\%)$ & $45.7 \pm 10.4$ & $48.7 \pm 12.7$ & \\
\hline IC (L) & $\mathrm{I} .8 \mathrm{I} \pm 0.43$ & $1.74 \pm 0.48$ & \\
\hline DL, CO \% pred & $72.4 \pm 25.2$ & $70.7 \pm 27.6$ & \\
\hline RV/TLC (\%) & $45.3 \pm 6.1$ & $48.5 \pm 8.8$ & \\
\hline Respiratory frequency & $19.3 \pm 4.4$ & $21.5 \pm 4.1$ & 0.04 \\
\hline Tidal volume $(\mathrm{mL})$ & $647 \pm 124$ & $618 \pm 165$ & \\
\hline Minute ventilation (L/minute) & $11.9 \pm 2.5$ & $12.4 \pm 2.6$ & \\
\hline Oxygen uptake (mL/minute) & $218 \pm 42.1$ & $230 \pm 53.6$ & \\
\hline $\mathrm{pH}$ & $7.41 \pm 0.02$ & $7.40 \pm 0.03$ & \\
\hline $\mathrm{PaO}_{2}(\mathrm{mmHg})$ & $86.5 \pm 11.9$ & $78.6 \pm 7.9$ & 0.002 \\
\hline $\mathrm{PaCO}_{2}(\mathrm{mmHg})$ & $37.9 \pm 4.3$ & $39.3 \pm 4.2$ & 0.024 \\
\hline Lactate (mEq/L) & $1.16 \pm 0.44$ & $0.96 \pm 0.30$ & \\
\hline Norepinephrine (ng/mL) & $0.61 \pm 0.32$ & $0.64 \pm 0.29$ & \\
\hline
\end{tabular}

Note: Data are presented as mean \pm standard deviation.

Abbreviations: \% pred, percent predicted; DL, CO, diffusing capacity for carbon

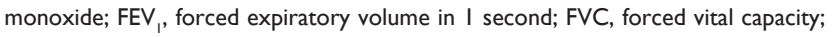
IC, inspiratory capacity; $\mathrm{PaCO}_{2}$, arterial carbon dioxide pressure; $\mathrm{PaO}_{2}$, arterial oxygen pressure; RV, residual volume; TLC, total lung capacity.

the tiotropium group. Borg scale scores at 2 minutes of exercise and submaximal isotime were significantly lower, and inspiratory capacity was significantly higher at 2 minutes of exercise and throughout exercise in the tiotropium group (Figure 3).

In incremental exercise testing, exercise time, carbon dioxide production, and $\mathrm{VE}$ at peak exercise were

Table 2 Comparison of the parameters at peak exercise between treatments with tiotropium and oxitropium in constant workload exercise testing

\begin{tabular}{lccl}
\hline & Tiotropium & Oxitropium & $P$ value \\
\hline Endurance time (s) & $504 \pm 29 \mathrm{I}$ & $397 \pm 20 \mathrm{I}$ & 0.007 \\
Work rate $(\mathrm{W})$ & $37.8 \pm 14.0$ & $32.5 \pm 13.3$ & $<0.00 \mathrm{I}$ \\
Oxygen uptake (mL/minute) & $756 \pm 227$ & $795 \pm 267$ & $0.03 \mathrm{I}$ \\
Carbon dioxide & $768 \pm 256$ & $799 \pm 304$ & \\
production (mL/minute) & & & \\
Oxygen uptake/weight & $13.3 \pm 4.0$ & $14.1 \pm 4.6$ & 0.035 \\
(mL/kg/minute) & & & \\
Minute ventilation (L/minute) & $30.7 \pm 7.9$ & $31.1 \pm 9.6$ & \\
$\mathrm{IC}(\mathrm{mL})$ & $1536 \pm 494$ & $1508 \pm 493$ & \\
Heart rate (beats/minute) & $118 \pm 16.1$ & $115 \pm 17.3$ & \\
SpO $(\%)$ & $91.4 \pm 4.6$ & $90.8 \pm 3.7$ & \\
Dyspnea index (\%) & $86.2 \pm 17.7$ & $98.2 \pm 21.8$ & 0.002 \\
$\mathrm{HR} /$ predicted maximum & $78.5 \pm 11.0$ & $76.8 \pm 12.3$ & \\
HR (\%) & & & \\
\hline
\end{tabular}

Notes: ${ }^{a}$ Dyspnea index $(\%)=$ (minute ventilation at peak exercise) $/($ maximal

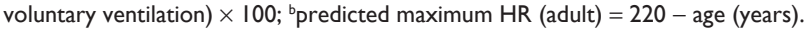
Abbreviations: $\mathrm{HR}$, heart rate; IC, inspiratory capacity; $\mathrm{SpO}_{2}$, oxygen saturation. 

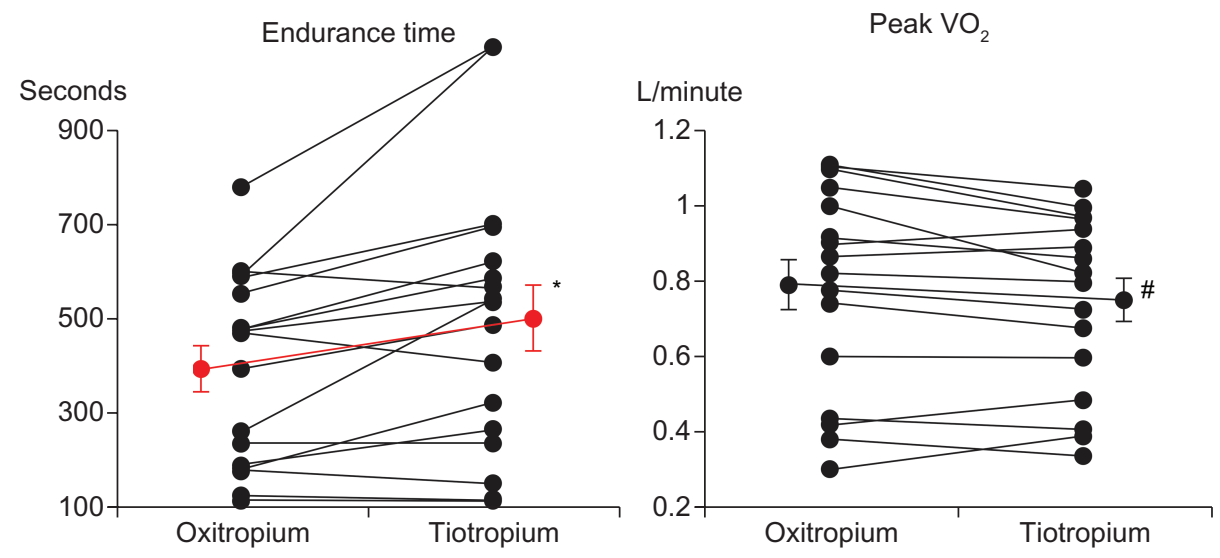

Figure 2 Comparisons of endurance time and peak oxygen uptake $\left(\mathrm{VO}_{2}\right)$ in constant-load cycle exercise between treatments with tiotropium and oxitropium. Notes: $* P=0.007 ;{ }^{*} P=0.031$. Bars represent mean \pm standard error.

significantly higher in the tiotropium group than in the oxitropium group (Table 3 and Figure 4). However, the differences were relatively small. The exercise times were longer for four patients in the oxitropium group (in which three patients discontinued exercise due to leg fatigue). The Borg scale scores $(P=0.009)$ and concentrations of plasma norepinephrine $(P=0.015)$ were significantly lower at submaximal isotime and throughout exercise in the tiotropium group (Figure 5). No differences in VE, output of carbon dioxide, arterial lactate, arterial blood gases, oxygen uptake, or HR at submaximal isotime between the two groups were found in incremental exercise testing. Longer exercise time was significantly correlated with an increase in VE at peak exercise $(r=0.59, P=0.015)$.

The difference in exercise time between the tiotropium and oxitropium groups (43.3 \pm 64.4 seconds) was more strongly correlated with differences in VE $(r=-0.72$, $P=0.001)$, oxygen uptake $(r=-0.76, P=0.0004)$, arterial $\mathrm{pH}(r=0.61, P=0.0114)$, arterial norepinephrine level $(r=-0.66, P=0.0044)$, carbon dioxide production $(r=-0.81, P<0.0001)$, and arterial lactate level $(r=-0.79$, $P<0.0001)$ at submaximal isotime than with other parameters of pulmonary function or CPET in incremental exercise (Figure 6, Table 4). The increase in exercise time was caused by the decrease in oxygen uptake and VE for submaximal workload and the suppression of combined respiratory and lactic acidosis progression.

At submaximal isotime, this difference in plasma norepinephrine $(-0.26 \pm 0.37 \mathrm{ng} / \mathrm{mL})$ was significantly correlated with differences between the two groups in respiratory frequency $(r=0.60, P=0.0135), \mathrm{HR}(r=0.68, P=0.0026)$, arterial $\mathrm{pH}(r=-0.64, P=0.0063), \mathrm{VE}(r=0.66, P=0.0042)$, oxygen uptake $(r=0.56, P=0.0219)$, and carbon dioxide production $(r=0.62, P=0.0101)$ (Figure 7 , Table 5$)$. The suppression of sympathetic activation resulted from the improvement of ventilatory efficiency, causing the reduction in oxygen uptake and HR.

Each of the patients was instructed to record daily his or her inhalation compliance and adverse events. Dry mouth was found in two cases of oxitropium treatment and in one
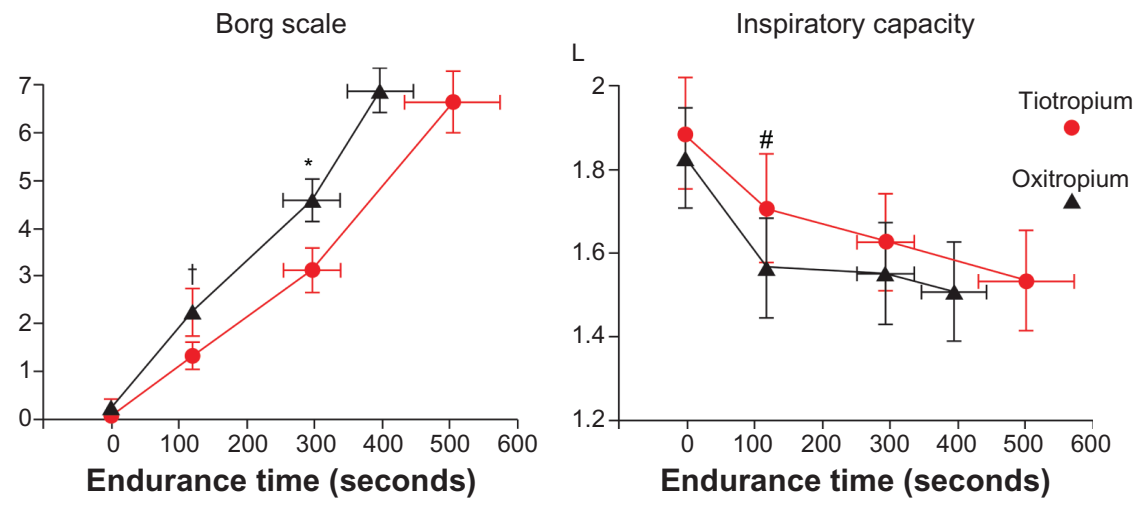

Figure 3 Borg scale and inspiratory capacity in constant work-load exercise testing. Notes: ${ }^{\dagger} P=0.015 ;{ }^{*} P=0.022 ;{ }^{*} P=0.014$. Bars represent mean \pm standard error. 
Table 3 Comparison of the parameters at peak exercise between treatments with tiotropium and oxitropium in incremental exercise testing

\begin{tabular}{|c|c|c|c|}
\hline & Tiotropium & Oxitropium & $P$-value \\
\hline Exercise time (s) & $54 I \pm 227$ & $498 \pm 217$ & 0.014 \\
\hline Oxygen uptake (mL/minute) & $855 \pm 287$ & $821 \pm 275$ & \\
\hline $\begin{array}{l}\text { Carbon dioxide } \\
\text { production ( } \mathrm{mL} / \text { minute) }\end{array}$ & $923 \pm 362$ & $889 \pm 356$ & 0.042 \\
\hline $\begin{array}{l}\text { Oxygen uptake } / \text { weight } \\
(\mathrm{mL} / \mathrm{kg} / \text { minute })\end{array}$ & $15.0 \pm 4.8$ & $14.5 \pm 4.7$ & \\
\hline $\begin{array}{l}\text { Oxygen uptake } \\
\text { (\% predicted) }\end{array}$ & $63.8 \pm 25.7$ & $61.5 \pm 24.5$ & \\
\hline Minute ventilation (L/minute) & $34.4 \pm 10.9$ & $32.6 \pm 10.5$ & 0.012 \\
\hline Heart rate (beats/minute) & $125 \pm 17.8$ & $122 \pm 16.4$ & \\
\hline $\mathrm{PaO}_{2}(\mathrm{mmHg})$ & $67.1 \pm 12.4$ & $69.6 \pm 17.8$ & \\
\hline $\mathrm{PaCO}_{2}(\mathrm{mmHg})$ & $43.0 \pm 5.0$ & $43.7 \pm 5.9$ & \\
\hline Dyspnea index (\%) & $95.7 \pm 19.2$ & $102.0 \pm 25.9$ & \\
\hline $\begin{array}{l}\text { HR/predicted maximum } \\
\text { HR (\%) }\end{array}$ & $83.1 \pm 12.4$ & $81.6 \pm 11.6$ & \\
\hline Lactate $(\mathrm{mEq} / \mathrm{L})$ & $4.2 \pm 1.7$ & $3.7 \pm 1.8$ & \\
\hline Norepinephrine (ng/mL) & $1.95 \pm 0.63$ & $2.08 \pm 0.81$ & \\
\hline
\end{tabular}

Notes: ${ }^{a}$ Dyspnea index $(\%)=$ (minute ventilation ( $\mathrm{L} /$ minute) at peak exercise $) /$ (maximal voluntary ventilation $(\mathrm{L} /$ minute $) \times 100$; ${ }^{\mathrm{b}}$ predicted maximum $\mathrm{HR}$ (adult) $=$ 220 - age (years). Data are presented as mean \pm standard deviation.

Abbreviations: $\mathrm{HR}$, heart rate; $\mathrm{PaCO}_{2}$, arterial carbon dioxide pressure; $\mathrm{PaO}_{2}$, arterial oxygen pressure.

case of tiotropium treatment. Urinary retention was also found in two oxitropium cases and in one tiotropium case. All patients completed their medication compliance, except for one patient who did not inhale oxitropium frequently. Thus, no patients discontinued this clinical trial due to the adverse effects of medications, and the study was completed with good compliance.

\section{Discussion}

We evaluated the differences in therapeutic effectiveness between tiotropium and oxitropium on pathophysiology during exercise in stable patients with COPD. On Visits 3 and 4 after a 6-week treatment period, patients underwent pulmonary function tests and incremental and constant-load CPET between 12:00 $\mathrm{pm}$ and 3:00 pm. The therapeutic effects of the two drugs were considered to be at steady state during this time of day, which was also well suited for evaluating their effectiveness in daily life. Compared with oxitropium, tiotropium provided more effective improvements in patient exercise performance as evaluated by both symptom-limited incremental and constant-load CPET using a cycle ergometer. The effect on endurance time using constant-load CPET was most beneficial and was associated with a reduction in lung dynamic hyperinflation and exertional dyspnea (Figure 3). These observations are consistent with those of previous studies that conducted comparisons with a placebo. ${ }^{6}$ Unfortunately, the concentration of norepinephrine could not be measured during the constant-load exercise, because of the complexity of combining arterial blood sampling and an inspiratory capacity maneuver at the same time during the exercise. In addition, the cost of arterial blood gas analyses and measurements of catecholamines was prohibitive.

We previously reported that arterial norepinephrine levels increased rapidly beyond the threshold, similar to the intensity of dyspnea, during incremental exercise in stable patients with COPD, regardless of their exercise capacity., ${ }^{910}$ In this study, Borg scale scores and plasma norepinephrine concentrations also increased in the same manner during incremental exercise. Exertional dyspnea and sympathetic activation (Borg scale scores: $3.1 \pm 1.9$, norepinephrine: $1.07 \pm 0.36 \mathrm{ng} / \mathrm{mL}$ ) significantly improved at the submaximal isotime and throughout exercise in the tiotropium group compared with those in the oxitropium group (Borg scale scores: $4.4 \pm 2.4$, norepinephrine: $1.34 \pm 0.52 \mathrm{ng} / \mathrm{mL}$ ) (Figure 5). This decrease in norepinephrine levels at the
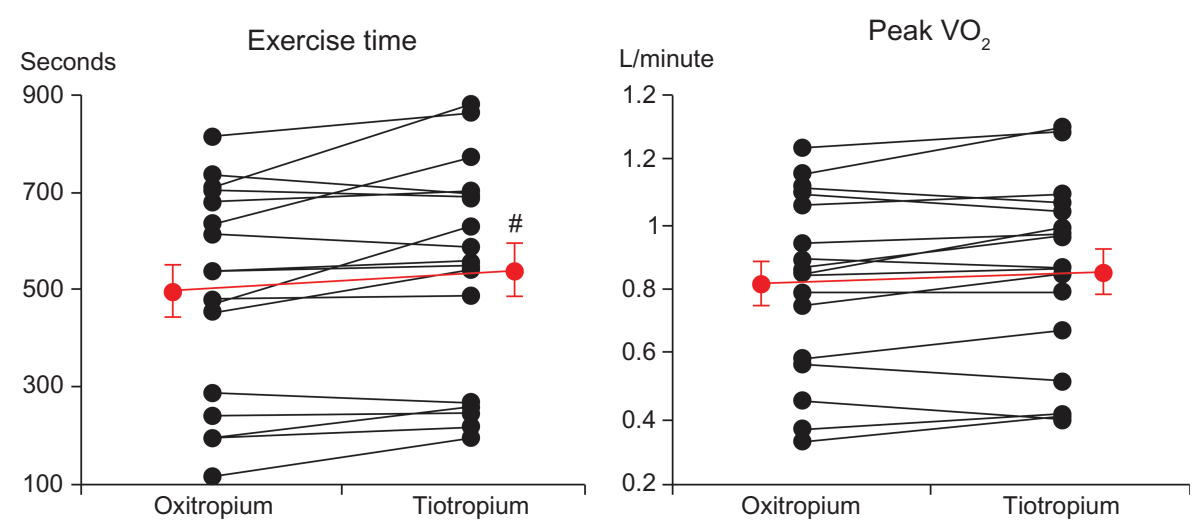

Figure 4 Comparisons of exercise time and peak oxygen uptake $\left(\mathrm{VO}_{2}\right)$ in incremental exercise between treatments with tiotropium and oxitropium. Notes: ${ }^{\#} P=0.014$. Bars represent mean \pm standard error. 

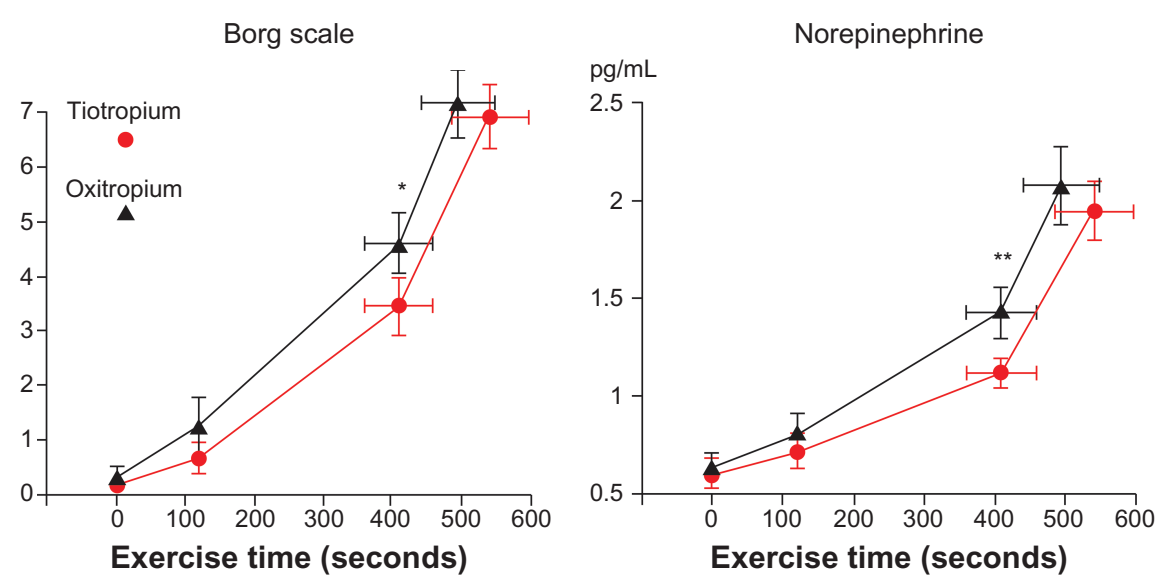

Figure 5 Borg scale and concentration of plasma norepinephrine in incremental exercise testing.

Notes: $* P=0.009 ; * * P=0.015$. Bars represent mean \pm standard error.

submaximal isotime was significantly and negatively correlated with longer exercise time (Figure 6). Lactate concentrations also increased beyond the inflection point (lactic threshold) during exercise. However, no significant differences were found between plasma lactate concentrations at the submaximal isotime (tiotropium $2.84 \pm 1.15 \mathrm{mEq} / \mathrm{L}$ vs oxitropium $2.75 \pm 1.28 \mathrm{mEq} / \mathrm{L}$ ) or at peak exercise. Overall, these findings indicate that tiotropium depressed sympathetic activation with improvement in dyspnea during exercise compared with oxitropium.

Whereas the CV safety of tiotropium has been questioned, results of the UPLIFT trial and a recent pooled analysis of data from 30 trials of tiotropium demonstrated that tiotropium is associated with reductions in the risk of all-cause mortality, CV mortality, and CV events. ${ }^{7,8}$ The selectivity for M3- over M2-receptors may also confer a clinical advantage. Accordingly, clinically significant treatment-related disorders of conduction or rhythm or changes in HR were not observed with tiotropium. From all these data, one may hypothesize that tiotropium will suppress the increase of sympathetic activation during exercise, as compared with the effect of oxitropium. A placebo-control study would have been more appropriate but could not be conducted due to certain ethical considerations. Short-acting anticholinergics have been confirmed to be effective for the management of COPD and are very popular in Japan.

"Submaximal isotime" was defined as the end of the stage 2 minutes prior to the shorter peak exercise, and represented the same intensity of workload. At this isotime, differences in several parameters, including reductions in VE, oxygen uptake, carbon dioxide production, and reduced progression of arterial acidosis, were significantly associated with improvements in exercise performance (Figure 6). The decreased ratios of oxygen uptake or carbon dioxide production versus power (W) likely indicate that the metabolic
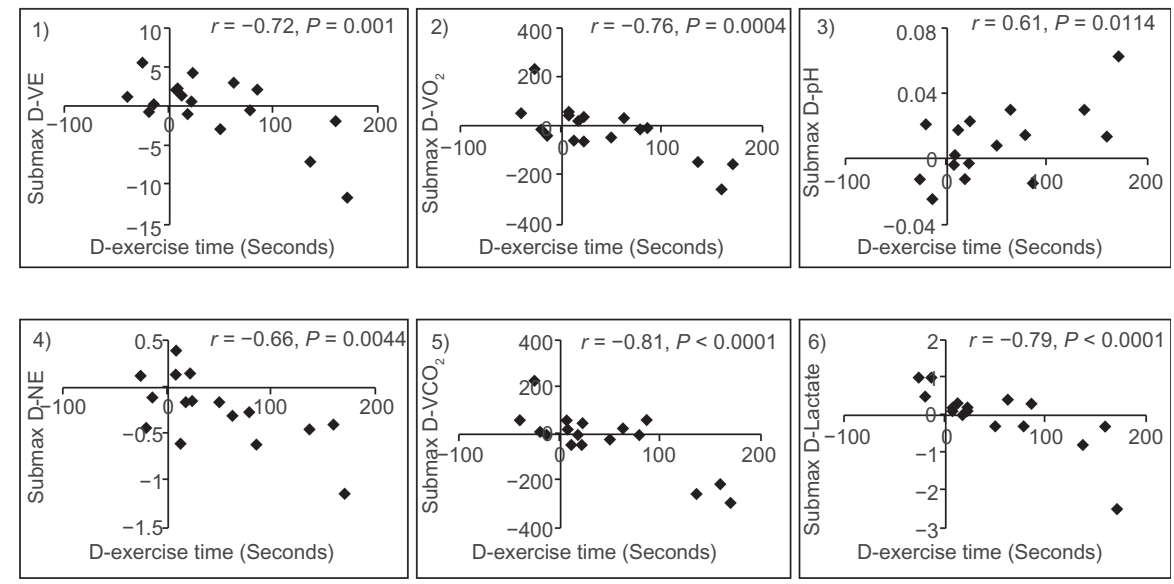

Figure 6 The degree of difference in exercise time correlated with the differences in ventilation (D-VE), oxygen uptake (D-VO $)$, arterial pH (D-pH), norepinephrine (D-NE), carbon dioxide production ( $\mathrm{D}-\mathrm{VCO}_{2}$ ), and lactate (D-Lactate) at submaximal identical levels in incremental exercise. 
Table 4 Analysis of contributing factors for the differences in exercise time between both groups

\begin{tabular}{|c|c|c|c|c|c|}
\hline \multirow[t]{2}{*}{ Contributing factors } & \multicolumn{3}{|c|}{ Simple regression } & \multicolumn{2}{|c|}{$\begin{array}{l}\text { Multiple regression (backward } \\
\text { variable selection } P<0.05 \text { ) }\end{array}$} \\
\hline & $\begin{array}{l}\text { Regression } \\
\text { coefficient }\end{array}$ & $\begin{array}{l}95 \% \text { confidence } \\
\text { interval }\end{array}$ & $P$ value & $\begin{array}{l}\text { Regression } \\
\text { coefficient }\end{array}$ & $\begin{array}{l}95 \% \text { confidence } \\
\text { interval }\end{array}$ \\
\hline Submax D-Minute ventilation (L/minute) & -10.970 & $(-17.033,-4.908)$ & 0.0002 & & \\
\hline Submax D-Oxygen uptake (mL/minute) & -0.457 & $(-0.672,-0.24 I)$ & $<0.0001$ & -0.251 & $(-0.465,-0.038)$ \\
\hline Submax D-Arterial pH & -0.409 & $(430.835,3061.407)$ & 0.013 & & \\
\hline Submax D-Norepinephrine (ng/mL) & -|| 1.811 & $(-185.165,-38.457)$ & 0.0006 & & \\
\hline Submax D-Carbon dioxide & $|746.12|$ & $(-0.573,-0.246)$ & $<0.0001$ & & \\
\hline \multicolumn{6}{|l|}{ production (mL/minute) } \\
\hline Submax D-Lactate $(\mathrm{mEq} / \mathrm{L})$ & $-6 I .46 \mid$ & $(-88.392,-34.530)$ & $<0.0001$ & $-4 I .255$ & $(-70.117,-12.393)$ \\
\hline
\end{tabular}

Abbreviation: $\mathrm{D}$, difference.

efficiency of oxygen utilization in the muscles improved and then suppressed the progression of acidosis (respiratory and lactic), which induced ventilatory drive in the medullary respiratory center. ${ }^{15}$ The reduction in VE response to the same workload was clearly associated with those of oxygen uptake $(r=0.717, P=0.0001)$ and carbon dioxide production $(r=0.883, P<0.0001)$ and suppression of progressive lactic acidosis $(r=0.882, P<0.0012)$. These effects on pathophysiology may be partially related to the basis of therapeutic action of tiotropium (eg, improvements in pulmonary function and ventilatory capacity) in stable patients with COPD.

The decrease in norepinephrine level, an expression of sympathetic activation, had a significant positive correlation with a decrease in respiratory frequency, HR, VE, oxygen uptake, and carbon dioxide production at submaximal isotime (Figure 7). In addition, it was negatively correlated with reduced progression of arterial acidosis. These diminished effects on VE and oxygen uptake response to the same workload during exercise, which differed in the tiotropium and oxitropium groups, were associated with suppression of sympathetic activation. The improvement in exercise time also correlated strongly with a decrease in oxygen uptake and sympathetic activation at submaximal isotime. These results suggest that the improvement in exercise tolerance was associated with a decrease in the oxygen uptake response to work rate during exercise, in addition to an increase in ventilatory capacity. This decrease in oxygen uptake response to work rate may be attributable to suppression of sympathetic activation and HR with symptomatic improvement.

In a previous study, COPD patients with severely reduced exercise capacity (peak oxygen uptake $<654 \mathrm{~mL} /$ minute) demonstrated sympathetic overactivation at a low-grade workload (plasma norepinephrine level, $1.4 \pm 0.94 \mathrm{ng} / \mathrm{mL}$ at $20 \mathrm{~W}$ ), equivalent to light activities of daily living. ${ }^{10}$ The sympathetic nerve activity, estimated by an increase in
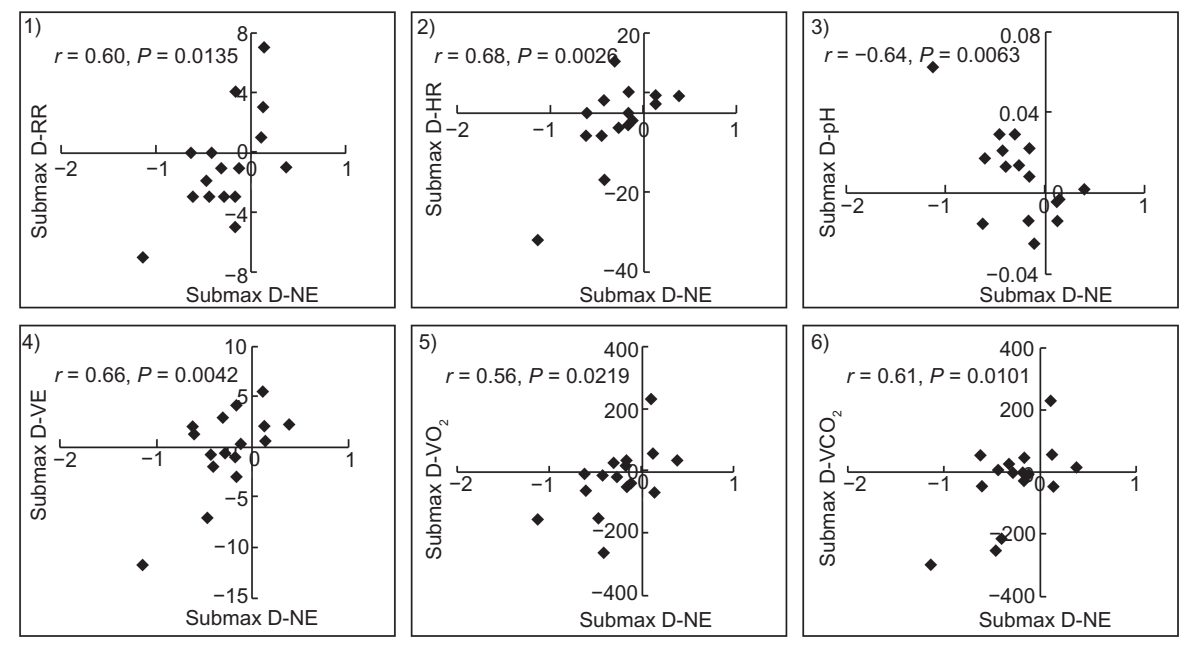

Figure 7 The difference in norepinephrine between the two groups correlated with the differences in respiratory frequency (D-RF), heart rate (D-HR), arterial $\mathrm{pH}(\mathrm{D}-\mathrm{pH})$, minute ventilation $(\mathrm{D}-\mathrm{VE})$, oxygen uptake $\left(\mathrm{D}-\mathrm{VO}_{2}\right)$, and carbon dioxide $\left(\mathrm{D}-\mathrm{VCO}_{2}\right)$ production at submaximal identical levels in incremental exercise. 
Table 5 Analysis of contributing factors for the differences in submax norepinephrine level between both groups

\begin{tabular}{|c|c|c|c|c|c|}
\hline \multirow[t]{2}{*}{ Contributing factors } & \multicolumn{3}{|c|}{ Simple regression } & \multicolumn{2}{|c|}{$\begin{array}{l}\text { Multiple regression (backward } \\
\text { variable selection } P<0.05 \text { ) }\end{array}$} \\
\hline & $\begin{array}{l}\text { Regression } \\
\text { coefficient }\end{array}$ & $\begin{array}{l}95 \% \text { confidence } \\
\text { interval }\end{array}$ & $P$ value & $\begin{array}{l}\text { Regression } \\
\text { coefficient }\end{array}$ & $\begin{array}{l}95 \% \text { confidence } \\
\text { interval }\end{array}$ \\
\hline Submax D-Respiratory frequency & 0.063 & $(0.014,0.112)$ & 0.015 & & \\
\hline Submax D-Heart rate (beats/minute) & 0.025 & $(0.010,0.040)$ & 0.003 & & \\
\hline Submax D-Arterial pH & -10.853 & $(-18.328,-3.374)$ & 0.008 & & \\
\hline Submax D-Minute ventilation (L/minute) & 0.057 & $(0.020,0.094)$ & 0.005 & 0.057 & $(0.020,0.094)$ \\
\hline Submax D-Oxygen uptake (mL/minute) & 0.002 & $(0.000,0.004)$ & 0.023 & & \\
\hline $\begin{array}{l}\text { Submax D-Carbon dioxide } \\
\text { production ( } \mathrm{mL} / \text { minute) }\end{array}$ & 0.002 & $(0.000,0.0003)$ & 0.012 & & \\
\hline
\end{tabular}

Abbreviation: $\mathrm{D}$, difference.

the arterial norepinephrine level/ $\Delta \mathrm{VO}_{2}$ and the norepinephrine threshold during exercise, was significantly associated with survival time. ${ }^{16}$ We previously demonstrated that acceleration of the sympathetic nervous system during light exercise is a predictor of poor prognosis in patients with COPD. ${ }^{16}$ Additional results indicating marked sympathetic activation in patients with COPD have recently been obtained. ${ }^{17-19}$ However, the manner in which tiotropium contributes to risk reduction of $\mathrm{CV}$ mortality and $\mathrm{CV}$ events has been poorly understood. The results of this study suggest that suppression of sympathetic activation during daily life activities may be one mechanism resulting in a reduction in the risk of $\mathrm{CV}$ mortality and $\mathrm{CV}$ events.

\section{Conclusion}

At the end of the 6-week treatment, tiotropium suppressed the increase of sympathetic activation during exercise, as compared with the effect of oxitropium. This effect might be attributed to improvement in lung function and exercise capacity and a reduction in exertional dyspnea, which were associated with decreases in respiratory frequency and HR and reduced progression of arterial acidosis.

\section{Acknowledgments}

This study was supported by a grant from the Osaka Tuberculosis Research Foundation. The study sponsors had no role in the study design; the collection, analysis, and interpretation of data; the writing of the manuscript; or the decision to submit the manuscript for publication. Editorial and publication support was provided by Editage. We thank Dr Eisei Oda (Medical TOUKEI Corporation) for the assistance of Statistical analysis.

\section{Disclosure}

The authors report no conflicts of interest in this work.

\section{References}

1. Rabe KF, Hurd S, Anzueto A, et al. Global strategy for the diagnosis, management, and prevention of chronic obstructive pulmonary disease. GOLD executive summary. Am J Respir Crit Care Med. 2008;177:743-751.

2. Vincken W, van Noord JA, Greefhorst AP, et al. Improved health outcomes in patients with COPD during 1 yr's treatment with tiotropium. Eur Respir J. 2002;19:209-216.

3. Restrepo RD. Use of inhaled anticholinergic agents in obstructive airway disease. Respir Care. 2007;52:833-851.

4. Anthonisen NR, Connett JE, Enright PL, Manfreda J; Lung Health Study Research Group. Hospitalizations and mortality in the Lung Health Study. Am J Respir Crit Care Med. 2002;166:333-339.

5. Barr RG, Bourbeau J, Camargo CA, Ram FS. Tiotropium for stable chronic obstructive pulmonary disease: a meta-analysis. Thorax. 2006;61:854-862.

6. O'Donnell DE, Fluge T, Gerken F, et al. Effects of tiotropium on lung hyperinflation, dyspnoea and exercise tolerance in COPD. Eur Respir J. 2004;23:832-840.

7. Tashkin DP, Celli B, Sen S, et al. A 4-year trial of tiotropium in patients with chronic obstructive pulmonary disease. N Engl J Med. 2008; 359:1543-1554.

8. Pedone $\mathrm{C}$, Incalzi RA. Tiotropium in chronic obstructive pulmonary disease. $N$ Engl J Med. 2009;360:185.

9. Maekura R, Hiraga T, Miki K, et al. The relationship between the increase in the concentration of plasma norepinephrine and the degree of dyspnea during exercise. Presented at the Congress of the European Respiratory Society, Vienna, Austria, 2003.

10. Maekura R, Hiraga T, Miki K, et al. Dynamic pathophysiology in stable COPD patients with severely reduced exercise capacity. Presented at the Congress of the European Respiratory Society, Amsterdam, The Netherlands, 2011.

11. Gardner RM, Hankinson JL, Clausen JL, Crapo RO, Johnson RO Jr, Epler GR. American Thoracic Society standardization of spirometry: 1987 update. Am Rev Respir Dis. 1987;136:1285-1298.

12. Miki K, Maekura R, Hiraga T, et al. Acidosis and raised norepinephrine levels are associated with exercise dyspnoea in idiopathic pulmonary fibrosis. Respirology. 2009;14:1020-1026.

13. O'Donnell DE, Lam M, Webb KA. Spirometric correlates of improvement in exercise performance after anticholinergic therapy in chronic obstructive pulmonary disease. Am J Respir Crit Care Med. 1999;160: 542-549.

14. Borg GA. Psychophysical basis of perceived exertion. Med Sci Sports Exerc. 1982;14:377-381.

15. ATS/ACCP. ATS/ACCP statement on cardiopulmonary exercise testing. Am J Respir Crit Care Med. 2003;167:211-277.

16. Yoshimura K, Maekura R, Hiraga T, Okuda Y, Hirotani A, Itou M. Sympathetic nervous stress during exercise is a good prognostic predictor in patients with COPD. Presented at the Congress of the European Respiratory Society, Vienna, Austria, 2003. 
17. Silken H, Matthelas L, Carl-Peter C, Gerd H, Stefan A. Marked sympathetic activation in patients with chronic respiratory failure. $\mathrm{Am}$ J Respir Crit Care Med. 2001;164:597-601.

18. Scalvini S, Porta R, Zanelli E, et al. Effects of oxygen on autonomic nervous system dysfunction in patients with chronic obstructive pulmonary disease. Eur Respir J. 1999;13:119-124.
19. Sakamaki F, Satoh T, Nagaya N, Kyotani S, Nakanishi N, Ishida Y. Abnormality of left ventricular sympathetic nervous function assessed by (123) I-metaiodobenzylguanidine imaging in patients with COPD. Chest. 1999;116:1575-1581.

\section{Publish your work in this journal}

The International Journal of COPD is an international, peer-reviewed journal of therapeutics and pharmacology focusing on concise rapid reporting of clinical studies and reviews in COPD. Special focus is given to the pathophysiological processes underlying the disease, intervention programs, patient focused education, and self management protocols.
This journal is indexed on PubMed Central, MedLine and CAS. The manuscript management system is completely online and includes a very quick and fair peer-review system, which is all easy to use. Visit http://www.dovepress.com/testimonials.php to read real quotes from published authors.

Submit your manuscript here: http://www.dovepress.com/international-journal-of-copd-journal 